\title{
Anatomical pathways related to the clinical findings in aneurysms of the anterior communicating artery ${ }^{1}$
}

\author{
JAMES ARTHUR TAREN
}

From the Neurosurgical Research Laboratory, the University of Michigan Medical School

Aneurysms of the anterior communicating artery are formidable lesions even when successfully treated surgically for they may produce long-standing ill effects that are out of proportion to the size of the lesion. Indeed, some of our operations which we have judged to be excellent from a technical standpoint have proved to be most disappointing as these patients may develop persistent mental and behavioural changes that prevent them from functioning normally in society.

Figure 1 illustrates this point. These are pre- and postoperative angiograms to document the presence of an aneurysm of the anterior communicating artery and show the obliteration of it by silver clips while preserving both anterior cerebral arteries. This patient was a successful middle-aged tool and die maker before a single episode of subarachnoid

${ }^{2}$ Presented at the Harvey Cushing meeting, Los Angeles, 19-22 April 1964. haemorrhage. Although the operation was performed over three years ago he is still unable to return to work because of persistent confusion and erratic behaviour. This aneurysm was unaccompanied by any intracortical clot and was obliterated as atraumatically as possible through a right subfrontal approach using urea and spinal drainage. However, dissection of the aneurysm from both parolfactory areas of Broca where it nestled was necessary.

Why does a small lesion in this area produce severe, long-term ill effects? In an attempt to explain this disturbance in function on the basis of an alteration in the structure of the areas, lesions were made if seven Macaques in the parolfactory area and/o? the anterior perforated area. A study of the resultank degeneration demonstrated the well-known fact thag this region is anatomically related to many othe areas of the brain and offers an explanation of some

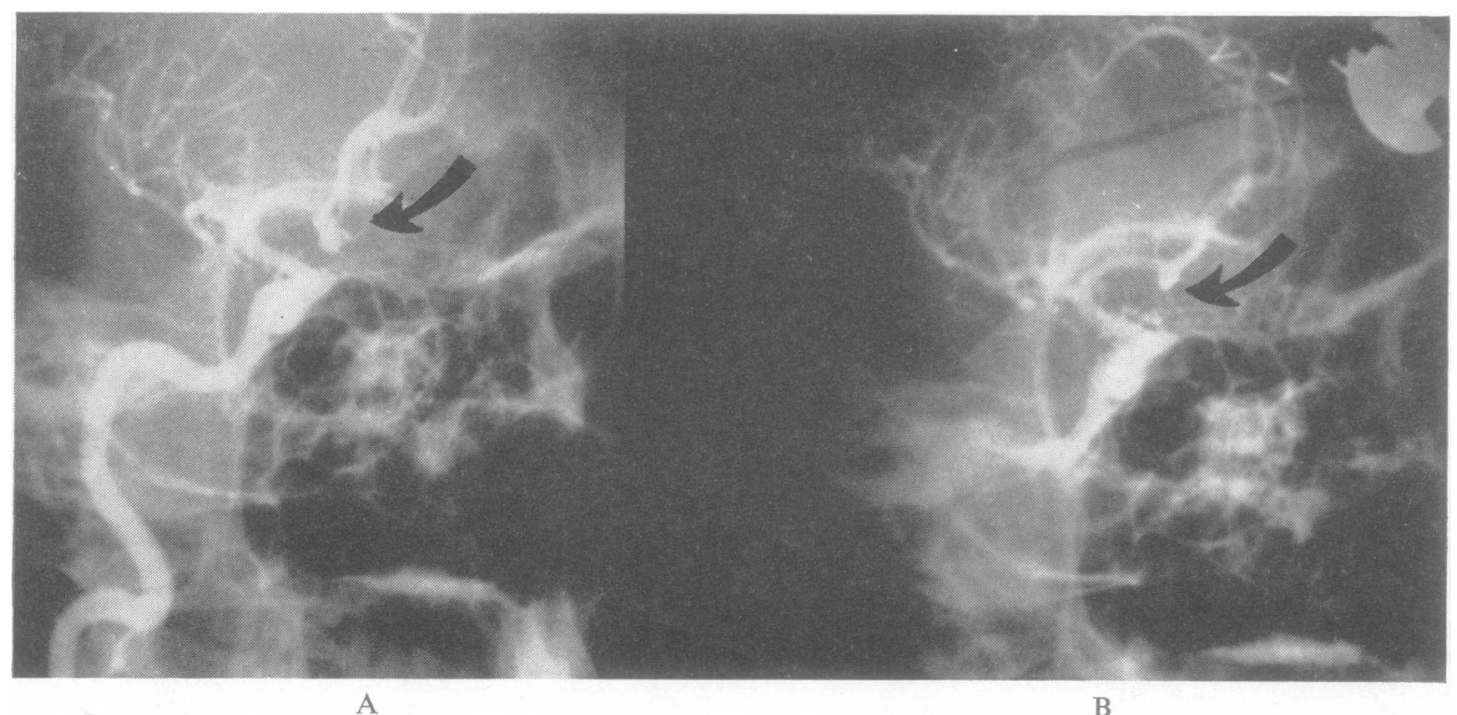

FIG. 1. A. Pre-operative oblique angiogram. The arrow indicates an aneurysm of the anterior communicating artery. B. A postoperative oblique angiogram. The arrow indicates a silver clip which has obliterated the aneurysm. 
of the clinical findings in man associated with lesions here.

Figure 2, a sagittal section of a human brain, illustrates some of the interconnexions of the precommissural septum (termed the parolfactory area of Broca in man) and the tuberculum olfactorium (the human anterior perforated space) and the proximity of the region to the anterior communicating artery. The precommissural area, which is very likely to be damaged by an anterior communicating aneurysm either from haemorrhage or from dissection during surgery, is connected to the hippocampus through the septo-hippocampal and hippocampal septal pathways that pass through the fornix. The cingulum provides a two-way association system between the precommissural area and the cingulate, parietal and fronto-occipital cortices as well as with the hippocampal gyrus. From the hippocampal gyrus there are interconnexions (not shown) with the amygdala. This septal area is also interconnected with the hypothalamus through the septo-hypothalamic and hypothalamo-septal components of the medial forebrain bundle. There is also a minor relationship of this area with the septum pellucidum. Some fibres penetrate the corpus callosum on their way from septal areas to the cingulum.

The parolfactory area of Broca and the anterior perforated space were destroyed under direct vision in seven monkeys using sterile conditions and with a minimum of damage to other areas of the brain. Two types of surgical approach were used to make the lesion: (1) a right subfrontal approach, and (2) a midline approach, retracting the right frontoparietal cortex laterally and splitting the corpus callosum (Fig. 3). The animals survived 17 days and were then sacrificed and Marchi preparations made. Serial sections of the brain were studied to ascertain

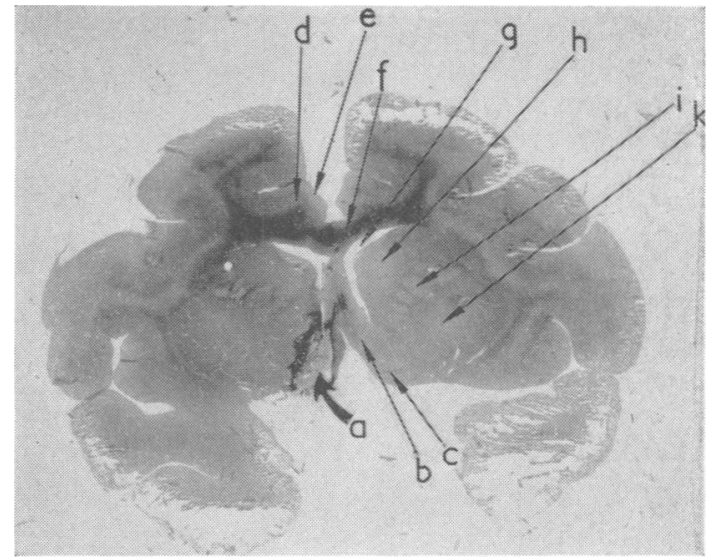

FIG. 3. Photomicrograph of a cross-section of Macaque brain, Marchi preparation in front of the foramen of Monro at the anterior limb of the internal capsule to demonstrate a lesion made by a midline approach. a. The lesion. b. Precommissural septum. c. Tuberculum olfactorium. d. Cingulum. e. Cingulate gyrus. f. Corpus callosum. g. Lateral ventricle. h. Head of the caudate nucleus. i. Anterior limb of the internal capsule. k. Putamen and globus pallidus.

the location of the resulting degeneration. Similar results were obtained in all the monkeys studied.

Figure 4 demonstrates degeneration in the tuberculo-septo-hippocampal pathway from a lesion in the tuberculo-septal area. These pathways between the precommissural septum and the hippocampus are represented by the striped white arrow of Figure 2. Septo-hippocampal connexions in primates have been described by several observers (Stoll, Ajmone-Marsan, and Jasper, 1951; Daitz and Powell, 1954; Green and Adey, 1956; Blackstad,

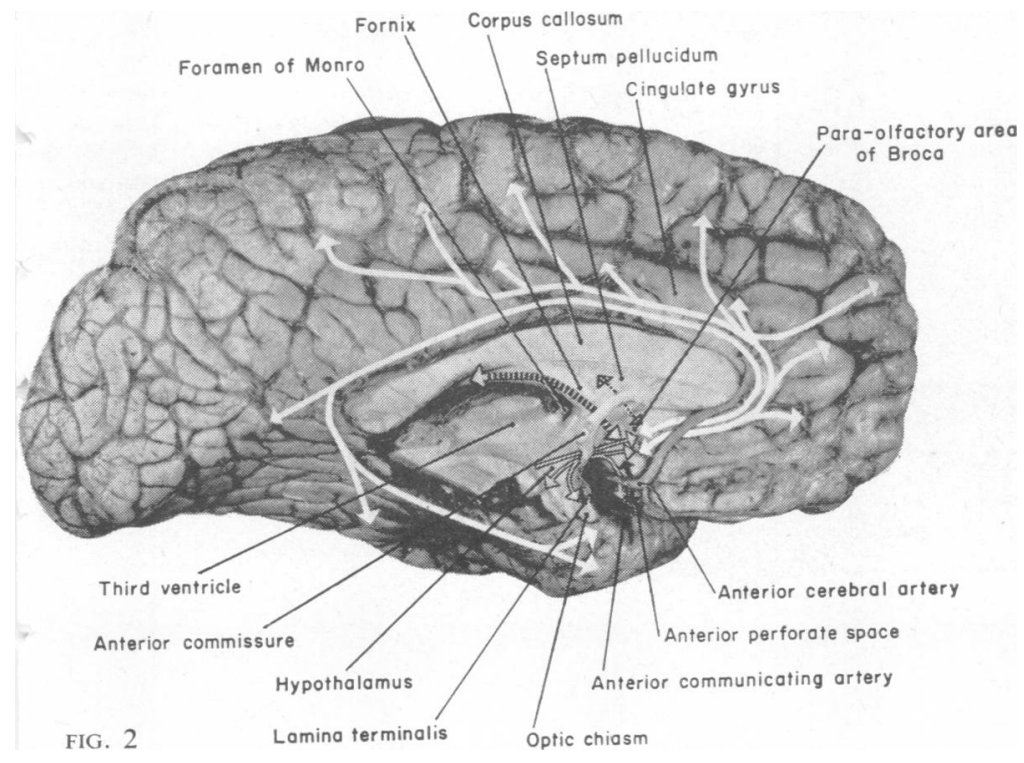

FIG. 2. The solid black arrow connects the parolfactory area of Broca with anterior perforated space. The solid white arrows represent the bi-directional connexion through the cingulum of the parolfactory area of Broca with the frontal lobe, parietal lobe, occipital lobe, and the hippocampal gyrus of the temporal lobe, with secondary connexions (not shown) to the amygdala. The outlined white arrows represent interconnexions of this area with the hypothalamus through the medial forebrain bundle. The striped white arrow represents the interconnexions of this area by way of the fornix with the hippocampus. The small dotted arrow represents a minor interconnexion of this area with the septum pellucidum. 


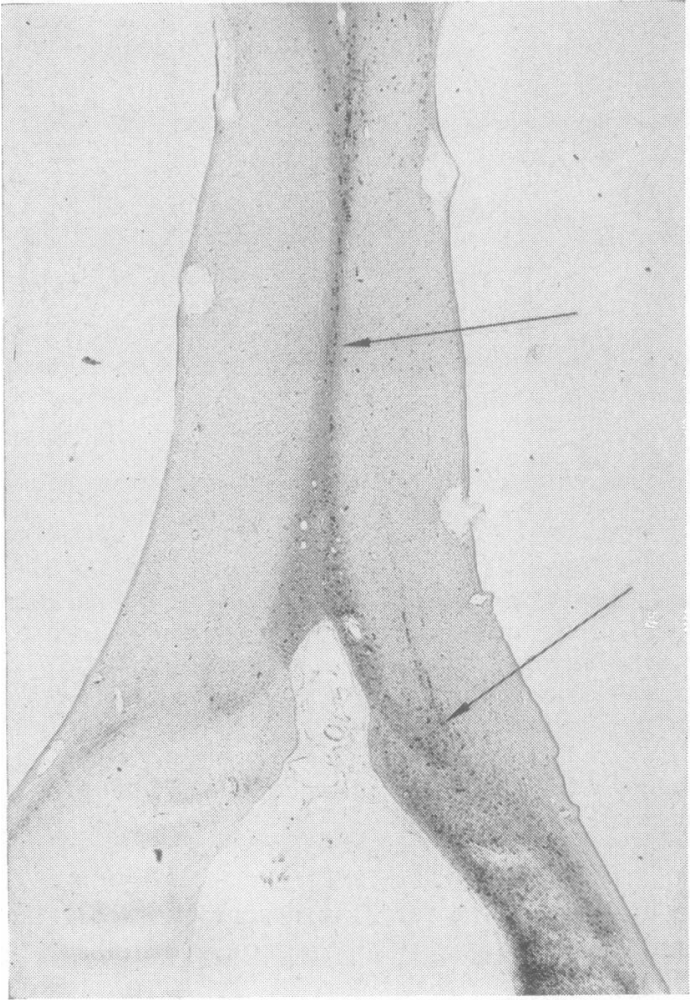

FIG. $4 \mathrm{a}$

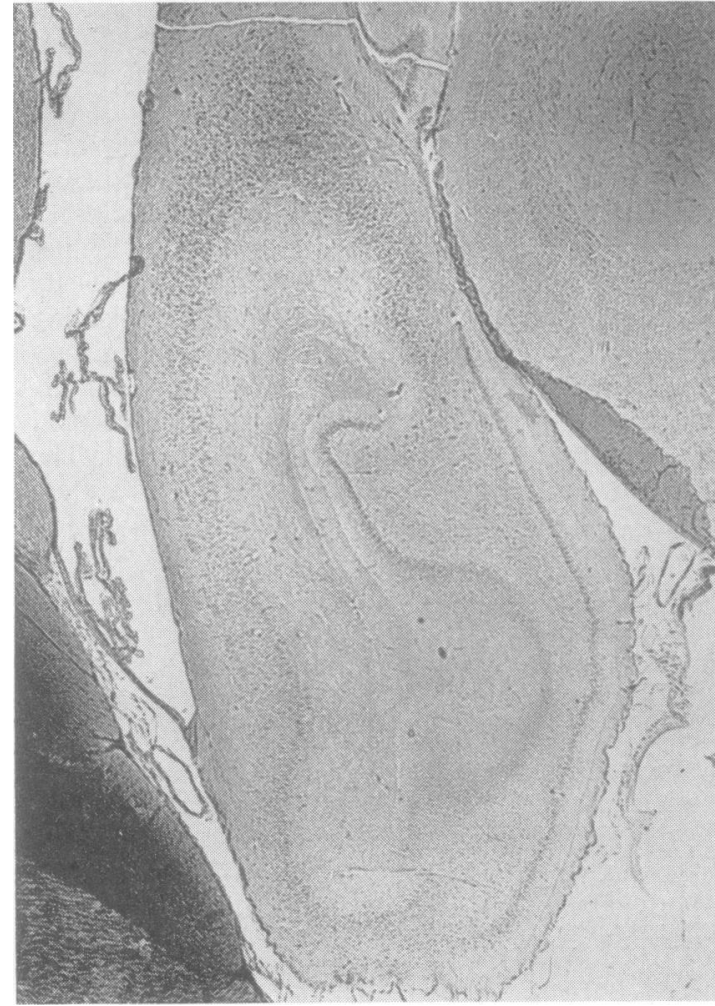

FIG. $4 \mathrm{c}$

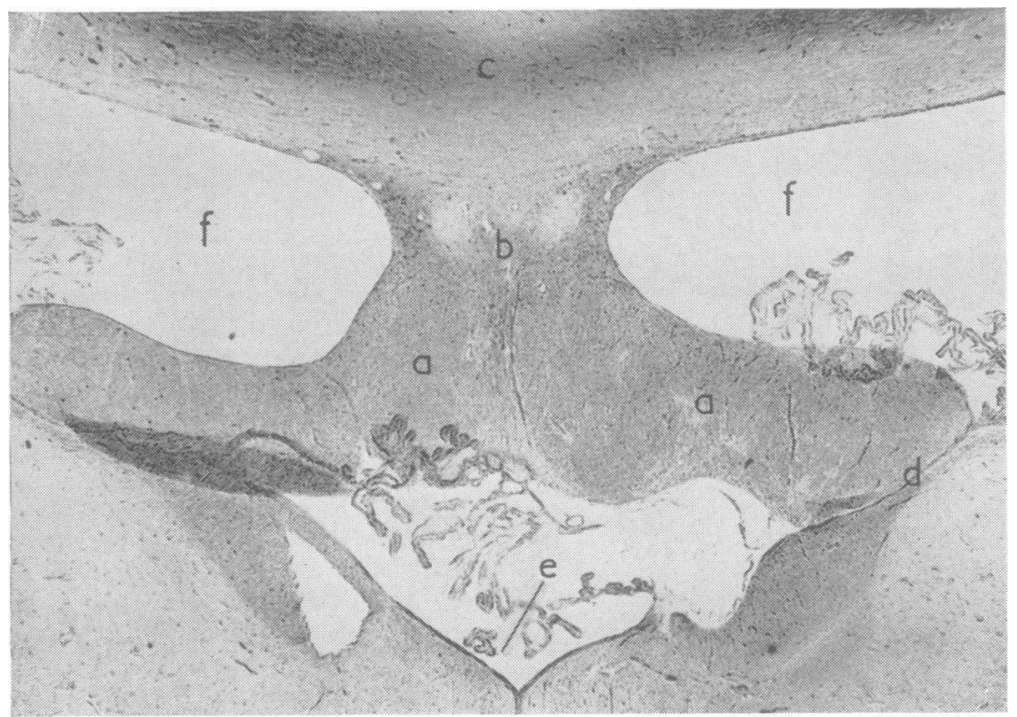

FIG. 4. Photomicrograph of cross-section of Macaque brain, Marchi preparation, to demon- $\mathbb{D}$ strate degeneration in the tuberculo-septo-hippocampal pathway. Series of sections is rostral to caudal. a. The arrows illustrate Marchi degeneration in. the region of the precommissurat septum. b. A region of the forni showing Marchi degeneration in:the fornices. a. Fornix with Marchi degeneration. b. Septumi pellucidum. c. Corpus callosum. 은 d. Near foramen of Monro. e. Third ventricle. f. Lateral ventricle. c. Cross-section to demonstrate Marchi degeneration in the hippocampus.

FIG. $4 b$ 


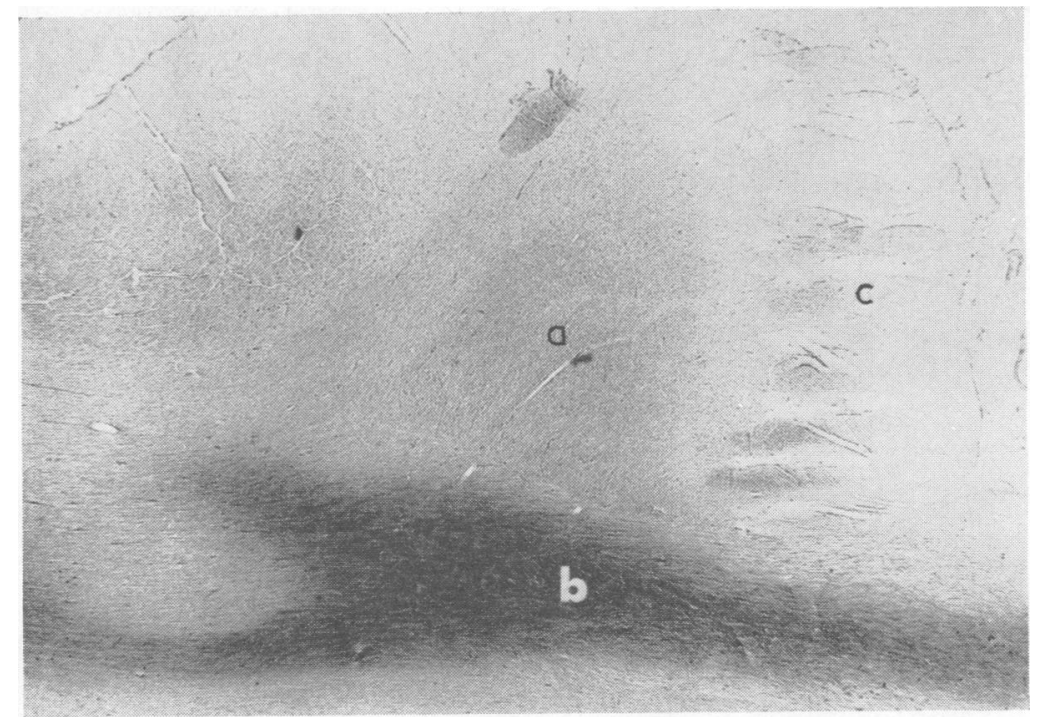

FIG. 5. Photomicrograph, Marchi preparation, cross-section of the cingulum in Macaque to show Marchi degeneration in the cingulum. a. Cingulum. b.Corpus callosum. c. Cingulate gyrus.

1958; and Votaw, 1960a and b). The hippocampus alerts the cerebral cortex, particularly visual, somesthetic, and some auditory areas, through its cortical association paths (Votaw, 1960a and b; and Schneider, Crosby, and Kahn, 1963). It follows that a lesion in precommissural septal areas may produce a diminution in the state of awareness, a form of cortical insufficiency due to reduced activation of the cortex by the hippocampus.

Figure 5 shows degeneration in the cingulum after a lesion in the tuberculo-septal area. The cingulum, composed of longer and shorter association fibres, provides a two-way association system between the anterior perforated space and the precommissural septum and perhaps the rostral part of the cingulate area, not only with areas in frontal and cingulate cortices but with entorhinal areas and hippocampal gyrus regions (Riley, 1943; Glees, 1948; Glees, Cole, Whitty, and Cairns, 1950; Adey and Meyer, 1952a and b; Schneider et al., 1963). The hippocampal gyrus interconnects the hippocampus and amygdala (Adey and Meyer, 1952a and b; Klingler and Gloor, 1960; and Schneider et al., 1963) with possibly a few cingulate fibres passing directly to these latter

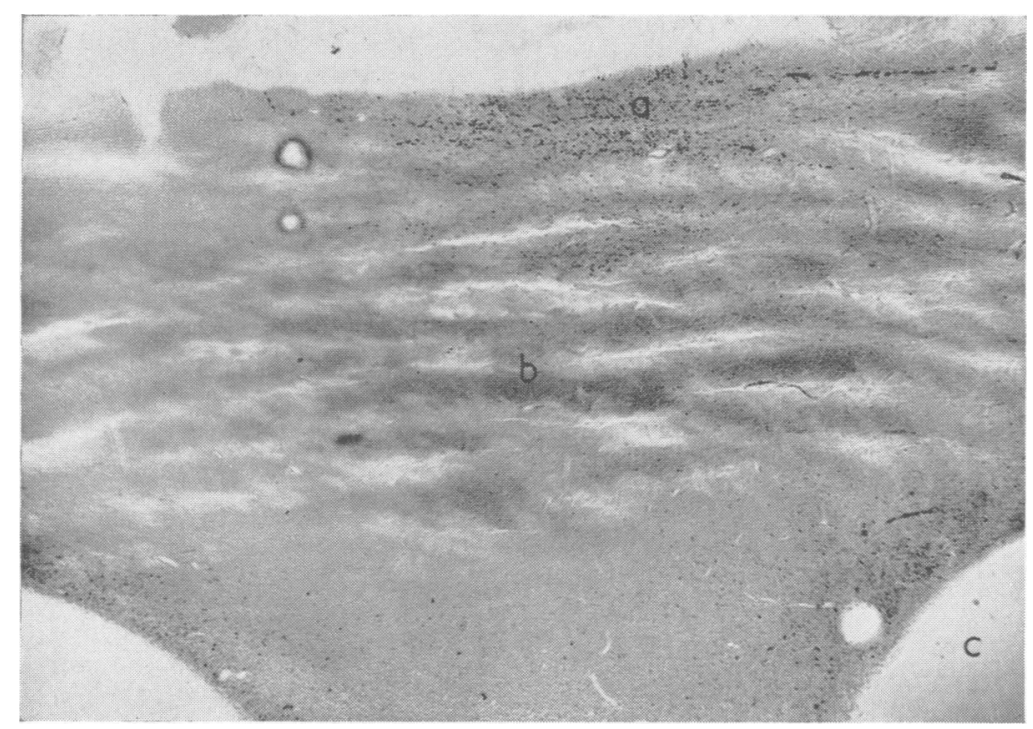

FIG. 6. Photomicrograph, Marchi preparation, a crosssection of macaque brain to demonstrate Marchi degeneration in the induseum griseum. a. Induseum griseum. b. Corpus callosum. c. Lateral ventricle. 

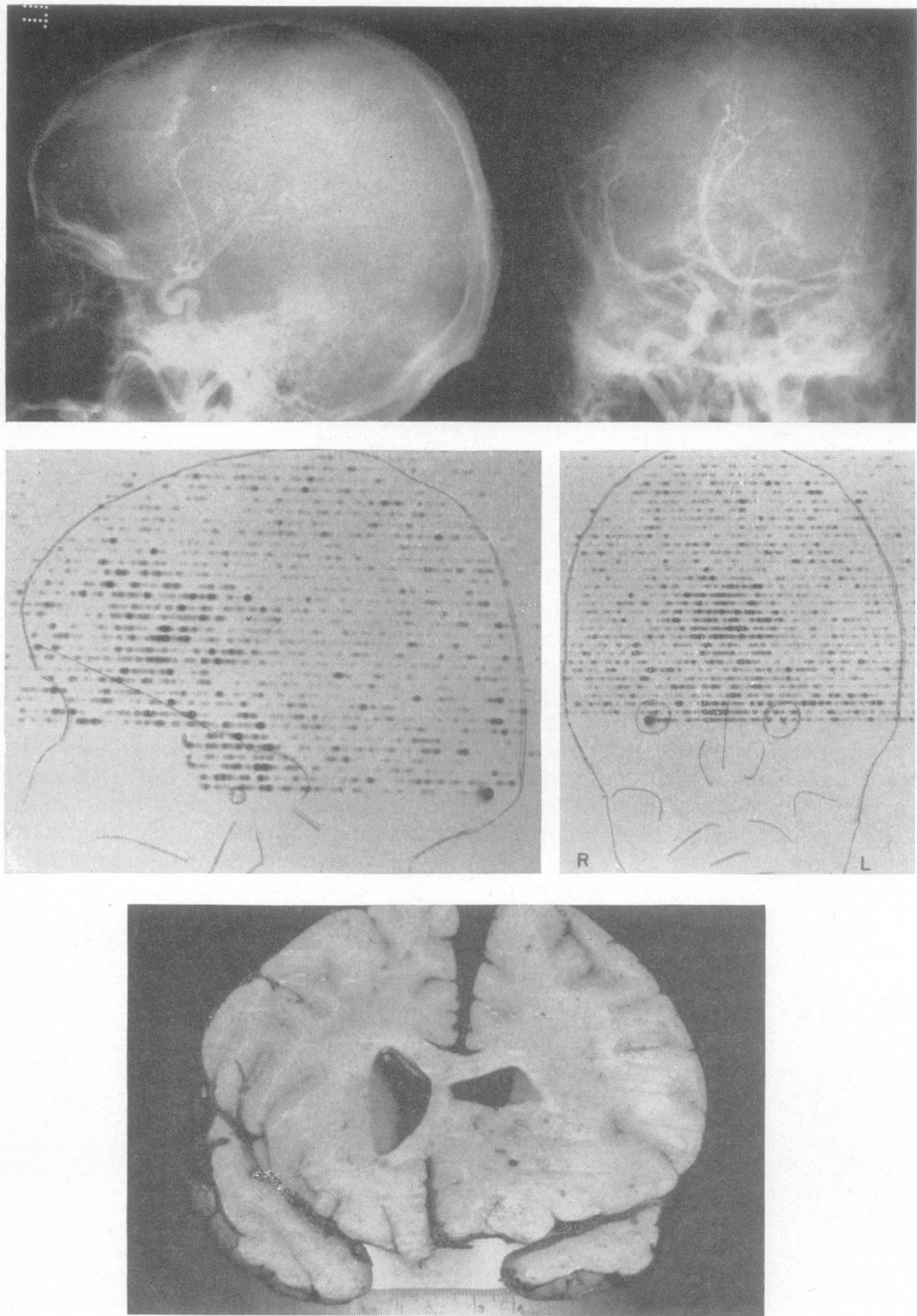

FIG. 7. Composite studies on the patient with the deep brain tumour. Note the left-to-right shift of the anterior cerebral artery in the angiogram and positive uptake of $\mathrm{Hg}^{203}$ near the frontal region in the midline. The cross-section of the brain at necropsy clearly demonstrates the tumour. 
areas (Schneider et al., 1963). Widely separated areas of the fornicate gyrus and adjacent frontal, parietal, and occipital cortices are interconnected through the cingulum. Overall diminution of cortical function, particularly in terms of poverty of association, is in part due to involvement of the septal portion of the cingulum (solid white arrows of Fig. 2) which interconnects the precommissural septum to the frontoparietal, occipital, and temporal cortices. The septal area is also connected to the induseum griseum (Fig. 6) which is a remnant of the anterior continuation of hippocampus. Thus the altered states of consciousness, the poor judgment, and the impoverished mental abilities which not infrequently occur after surgical treatment of anterior communicating artery aneurysms may in part at least be due to impairment of the septal part of these pathways.

The septal area is connected to the hypothalamus by the septo-hypothalamic and hypothalamo-septal components (outlined white arrows) of the medial forebrain bundle (Crosby and Woodburne, 1951;

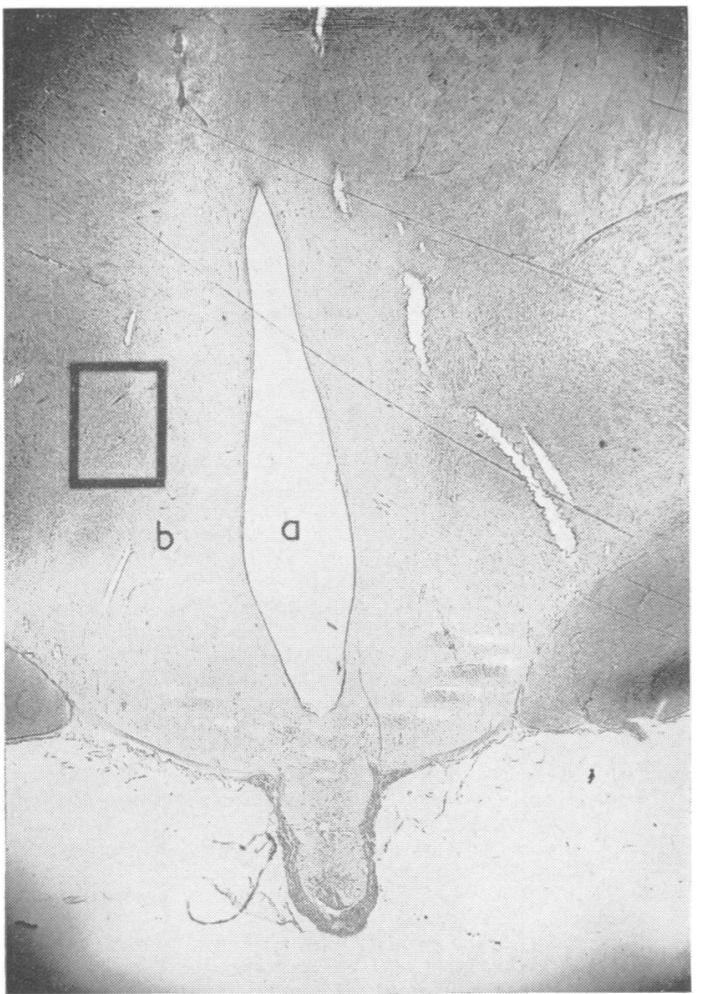

FIG. $8 \mathrm{~A}$
Kuhlenbeck, 1954; Ingram, 1956). It has long been known that a hypothalamic cat, that is, an animal in which the hypothalamus has been severed from the higher brain centres, will show signs of rage when stimulated (Bard, 1928; Bard, 1934; Bard and Mountcastle, 1948). Moreover, stimulation of the dorsomedial hypothalamic nucleus in a tame cat produces signs of a very angry animal (Ingram, 1956). The destruction of the ventromedial hypothalamic nucleus brings about almost like results. These responses are the 'sham' rage of experimentalists, that is, they represent the emotional expression of anger but not necessarily the emotion itself, which is cortical. The conditions furthering the elicitation of signs of rage under experimental conditions suggest that there is a regulation, under normal conditions, of hypothalamic responses by corticohypothalamic systems, such as the medial forebrain bundle (Bard and Rioch, 1937; Ingram, 1940; Kuhlenbeck, 1954).

Although the cortical centres (particularly the

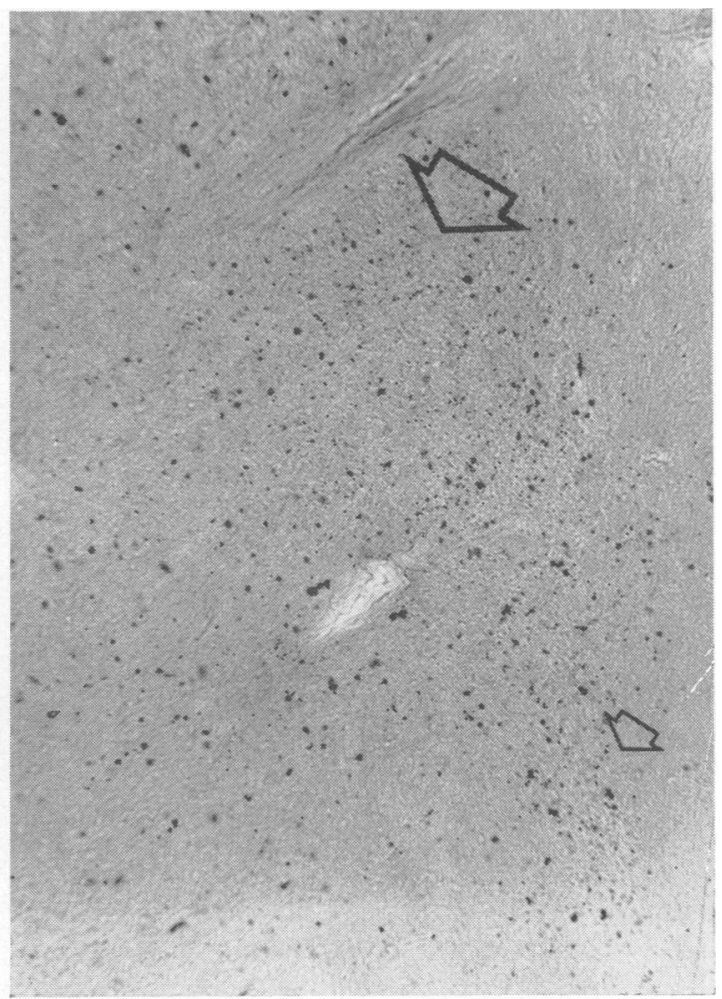

FIG. $8 \mathrm{~B}$

FIG. 8. Photomicrograph of a cross-section of Macaque brain to demonstrate Marchi degeneration in the medial forebrain bundle. A. Low magnification of this area. a. Third ventricle. b. The tuberal nuclei of the hypothalamus. The area outlined in black is the region in B where the large arrow illustrates Marchi degeneration in the septohypothalamic portion of the medial forebrain bundle and the small narrow illustrates Marchi degeneration on the septohypothalamic fibres as they course ventrally to terminate around the tuberal nuclei (perifornical, ventromedial, and dorsomedial) of the hypothalamus. 
cingulate, hippocampal, and frontal regions) are undoubtedly of greater importance in primates than in subprimates in determining emotional responses, and possibly there is some shift forward in the centres from which various responses can be elicited, still the septal-tubercular areas with their discharge path, the medial forebrain bundle, remain an important part of the mechanism by which the hypothalamic regulation of autonomic centres is put under cortical control.

A highly intelligent man was presented at our clinic because of a recent onset of changes in mood, attacks of rage, and increasing apathy, forgetfulness, and confusion (Fig. 7). He had been hypertensive for two to three years. An arteriogram demonstrated a left-to-right shift of the anterior cerebral artery. There was a positive uptake of $\mathbf{H g}^{203}$ near the frontal region in the midline. A glioblastoma multiforme involving the deep left frontal area was found at operation. The patient died shortly after.

In the the cross section of the brain at necropsy, tumour involved the parolfactory area of Broca and probably the anterior perforated space on the left. Figure 8 demonstrates Marchi degeneration in the septo-hypothalamic portion of the medial forebrain bundle after a lesion had been made previously in the septo-tuberculum area considerably rostral to this section. The hypothalamus is on the efferent side of the arc for emotional expression. It can be postulated that the patient's attacks of rage and emotional lability resulted from lack of cortical regulation of the hypothalamus due to destruction by the tumour of the parolfactory area and, secondarily, of the medial forebrain bundle.

\section{SUMMAR:Y}

The anatomical relation of the parolfactory area of Broca and the anterior perforated space to other areas of the brain is clearly demonstrated by Marchi degeneration after lesions in this area in Macaques. The parolfactory area of Broca and the anterior perforated space are interconnected with the hippocampus by way of the fornix; with the hypothalamus through the medial forebrain bundle; and through the cingulum with the frontal, temporal, parietal, cingulate, and occipital cortices. The parolfactory area of Broca and the anterior perforated space serve as way stations between the cerebral cortex and other regions of the brain.

The neurological deficits following lesions here appear out of proportion to the size of the lesion or may appear to be more characteristic of lesions in other areas of the brain. It is postulated that a lesion in this region, whether due to an aneurysm of an anterior communicating artery or a tumour, will interfere with the normal interplay of this area with other brain areas. The resultant clinical picture of mental and behavioural aberrations will depend on the degree and the type (destructive or irritative) of involvement.

This study suggests that the less dissection in this area, the better. It sheds some light on the more abstract functioning of the central nervous system.

This work would not have been possible without Dr. Elizabeth C. Crosby. I also wish to acknowledge the assistance of Parke, Davis \& Company in obtaining certain materials and U.S.P.H. grant B 3620-02.

\section{REFERENCES}

Adey, W. R., and Meyer, M. (1952a). An experimental study of hippocampal afferent pathways from prefrontal and cingulate areas in the monkey. J. Anat. (Lond.), 86, 58-74.

,$--(1952 b)$. Hippocampal and hypothalamic connections of the temporal lobe in the monkey. Brain, 75, 358-384.

Blackstad, T. W. (1958). On the termination of some afferents to the hippocampus and fascia dentata. Acta anat. (Basel), 35, 202-214.

Bard, P. (1928). A diencephalic mechanism for the expression of rage with special reference to the sympathetic nervous system. Amer. J. Physiol., 84, 490-515.

(1934). On emotional expression after decortication with some remarks on certain theoretical views. Psychol. Rev., 41, 309-3290 $\omega$ and Mountcastle, V. B. (1948). Some forebrain mechanisn involved in expression of rage with special reference to sufp pression of angry behavior. In The Frontal Lobes. Res. Pubh $\infty$ Ass. nerv. ment. Dis., 27, 362-404.

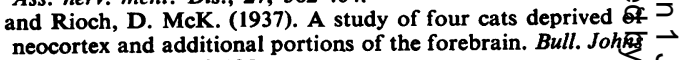
Hopk. Hosp., 60, 73-125.

Crosby, E. C. and Woodburne, R. T. (1951). The mammalian mi brain and isthmus regions. Part II. The fiber connections.

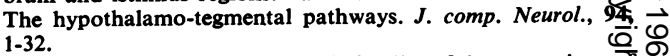

Daitz, H. M., and Powell, T. P. S. (1954). Studies of the connexions of the fornix system. J. Neurol. Neurosurg. Psychiat., 17, 75-82.

Glees, P. (1948). Die frontale Leukotomic im Lichte anatomischer Betrachtung, Klin. Wschr., 26, 127.

- Cole, J., Whitty, C. W. M., and Cairns, H. (1950). The effects of lesions in the cingular gyrus and adjacent areas in monkeys. $\bar{O}$ J. Neurol. Neurosurg. Psychiat., 13, 178-190.

Green, J. D., and Adey, W. R. (1956). Electrophysiological studies of $\frac{2}{(D}$ hippocampal connections and excitability. Electroenceph. $\varrho$ clin. Neurophysiol., 8, 245-262.

Ingram, W. R. (1940). Nuclear organization and chief connections of $\overline{\mathrm{O}}$ the primate hypothalamus. In The Hypothalamus. Res. Publ. 3 Ass. nerv. ment. Dis., 20, 195-244.

(1956). The hypothalamus. Ciba clin. Symp., 8, 117-156.

Klingler, J., and Gloor, P. (1960). The connections of the amygdala and of the anterior temporal cortex in the human brain. $J$. comp. Neurol., 115, 333-369.

Kuhlenbeck, H. (1954). The human diencephalon. A summary of development, structure, function, and pathology. Confin. neurol. (Basel), 14, suppl.

Riley, H. A. (1943). An Atlas of the Basal Ganglia, Brain Stem and Spinal Cord. Williams and Wilkins, Baltimore.

Schneider, R. C., Crosby, E. C., and Kahn, E. A. (1963). Certain afferent cortical connections of the rhinencephalon. In The Rhinencephalon and Related Structures, edited by W. Bargmann응 and J. P. Schádé, pp. 191-217. [Progress in Brain Research, Vol. 3.] Elsevier, Amsterdam, London, New York.

Stoll, J., Ajmone-Marsan, C., and Jasper, H. H. (1951). Electrophysio-을 logical studies of subcortical connections of anterior temporal
region in cat. $J$. Neurophysiol., 14, 305-316.

Votaw, C. L. (1960a). Study of septal stimulation and ablation in the macaque monkey. Neurology (Minneap.), 10, 202-209.

(1960b). Certain functional and anatomical relations of the cornu Ammonis of the macaque monkey, II. Anatomical relations. $\omega$ J. comp. Neurol., 114, 283-293. 